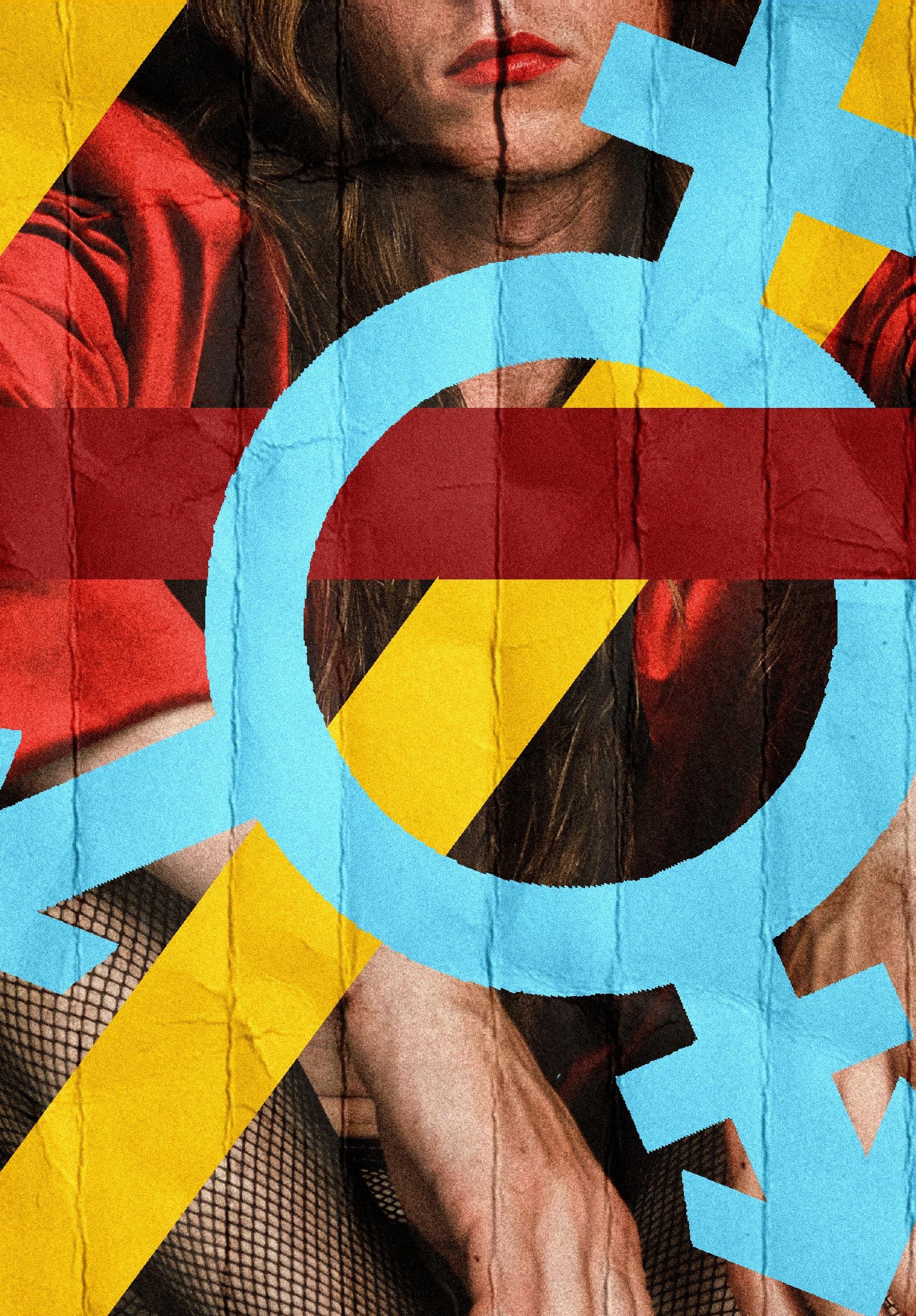




\title{
Conversando sobre gênero e sexualidade com adolescentes
}

Talking about gender and sexuality with teenagers

\author{
Luiza Andrade Pereira Ferrer Silva \\ Graduanda em Psicologia \\ Universidade do Estado de Minas Gerais \\ E-mail: luizaferrero1@outlook.com \\ Marla Ariana Silva \\ Enfermeira. Mestranda em Ciências \\ Universidade Federal de São João del-Rei \\ E-mail: marla_ariana@hotmail.com \\ Alexandre Coutinho de Melo \\ Enfermeiro \\ Universidade do Estado de Minas Gerais \\ E-mail: alexandre.m.coutinho@hotmail.com \\ Eduarda Pampolin Miessi Luchini \\ Psicóloga \\ Universidade do Estado de Minas Gerais \\ E-mail: eduarda.luchini@gmail.com \\ Camila Souza de Almeida \\ Universidade do Estado de Minas Gerais \\ E-mail: csalmeida_1@hotmail.com
} Enfermeira. Doutora em Ciências da Saúde. Docente de Enfermagem

\section{RESUMO}

A adolescência, ao longo da história, tem sido analisada de diversas formas, dependendo do contexto sociocultural em que o adolescente está inserido. Em alguns contextos, o periodo da adolescência não é considerado, já em outros, ele é conturbado e conflituoso. Tem como objetivo compreender quais as visões dos adolescentes acerca do assunto e promover o debate e suscitar dúvidas sobre as regras empregadas socialmente. Trata-se de um relato de experiência do projeto de extensão intitulado "Debatendo questões de gênero e sexualidade na escola", em que foram realizados grupos operativos com adolescentes de 13 a 15 anos de idade, em uma escola estadual de uma cidade do interior de Minas Gerais. O público alcançado foi de 16 adolescentes, com média de idade de 14 anos. Sugere-se a realização de educação permanente voltada aos professores das diversas disciplinas, pois, como educadores, esses influenciam a formação dos jovens pelo que falam e representam.

Palavra-chave: Adolescente, Identidade de Gênero, Sexualidade.

\section{ABSTRACT}

Adolescence, throughout history, has been analyzed in several ways, depending on the socio-cultural context in which the adolescent is inserted. In some contexts, the period of adolescence is not considered, while in others, it is troubled and conflicted. It aims to understand the views of adolescents on the subject and promote debate and raise doubts about the rules employed socially. This is an experience report of the extension project entitled "Debating gender and sexuality issues at school", in which operative groups were held with teenagers from 13 to 15 years old, in a state school in a city in the interior of Minas Gerais. The audience reached was 16 adolescents, with an average age of 14 years. It is suggested to carry out permanent education aimed at teachers of different disciplines, because, as educators, they influence the formation of young people by what they speak and represent.

Keyword: Adolescent, Gender Identity, Sexuality. 


\section{INTRODUÇÃO}

A adolescência, ao longo da história, tem sido analisada de diversas formas, dependendo do contexto sociocultural em que o adolescente está inserido, sendo que em alguns o período da adolescência não é considerado, já em outros, ele é conturbado e conflituoso (Trifoni, 2013).

No ocidente, esse período da vida é marcado por intensas mudanças físicas e psicossociais, em que o adolescente deseja novas experiências e sensações. Dentre elas, tem-se o interesse sexual. Esse surge em decorrência da puberdade, um evento considerado fisiológico, mas marcado pelos fatores sociais (Trifoni, 2013).

Com o despertar do interesse sexual, outros questionamentos vêm à tona, como os relativos ao gênero e às curiosidades acerca da sexualidade. Tais questões, caso não trabalhadas com os adolescentes, levantam dúvidas e os expõem a comportamentos de risco, sendo comuns as dúvidas quanto à diferença entre gêneros e sexualidade nessa faixa etária.

O presente artigo adota o termo sexualidade como algo inerente ao homem, que o afeta de maneira individualizada, especialmente aos adolescentes, que passam por mudanças que geram angústias e dúvidas sobre o assunto (Domingues et al., 2018; Morais et al., 2020). O gênero, por sua vez, é compreendido como algo que vai além do sexo biológico, pois é desenvolvido em cada individuo, levando-se em consideração as questões sociais, culturais e discursivas da época e do local onde se vive (Marcon et al., 2016). Outrossim, é caracterizado como algo performativo, isto é, que se dá pela imitação de atos daquilo pontuado como sendo de um gênero específico (Butler, 2018).

A sociedade contemporânea encontra-se envolta em paradigmas heteronormativos, que determinam a heterossexualidade como um padrão a ser seguido, e os adolescentes tendem a reproduzir esse modelo, conferindo-lhe o título de normal e natural, e tudo aquilo que foge da norma é considerado como anormal, patológico (Butler, 2018).

Perante essas considerações, e por estar interligado com as normas sociais e culturais, os individuos que não se enquadram na heteronormatividade estão expostos a maiores niveis de violência (Cerqueira et al., 2018). Por tudo isso, expõe-se que essa imposição de padrões deve ser discutida. E é necessário que estas discussões sejam realizadas em espaços sociais, como escolas e unidades de saúde.

A escola é uma instituição normativa, capaz de mudanças paradigmáticas e promoção de discussões, mas pode ser também um ambiente de reprodução social, que leva à perpetuação da desigualdade social e da violência. Tudo dependerá de como assuntos considerados tabus serão abordados pela direção e pelos professores (Morais et al., 2020).

Para que uma educação seja emancipadora e leve a mudanças a curto e a longo prazos, discussões acerca de regras sociais, como a heteronorma- 
tividade, a violência e as demais questões relacionadas a sexualidade devem ser discutidas, principalmente na adolescência, por ser periodo de grandes mudanças comportamentais e sociais (Campos et al., 2018).

Diante disso, e considerando-se a necessidade de discussão e do empoderamento dos adolescentes acerca da temática sexualidade e gênero, o projeto objetivou debater questões de gênero e sexualidade com adolescentes de um município do centro oeste mineiro. Nessa perspectiva, objetivou-se compreender quais as visões dos adolescentes acerca do assunto, promover o debate sobre preconceito e violência e suscitar a dúvida sobre regras empregadas socialmente.

\section{RELATO DE EXPERIÊNCIA}

O relato de experiência provém do projeto de extensão "Debatendo questões de gênero e sexualidade na escola", em que foram realizados grupos operativos com adolescentes de 13 a 15 anos de idade em uma escola estadual de uma cidade do interior de Minas Gerais.

A metodologia escolhida para se abordar a temática foi a dos grupos operativos, proposta pelo psiquiatra suiço-argentino Pichon-Rivièri, que considerava grupo como um aglomerado restrito de pessoas, ligados por tempo e espaço, propondo uma tarefa - explícita ou implicitamente - que se constitui como sua finalidade. Ademais, os individuos formam uma estrutura dinâmica chamada de vínculo, possibilitando que os participantes reflitam sobre seus costumes e encontrem meios de mudanças de suas concepções e comportamentos, algo fundamental para alcançar o objetivo do trabalho (Pichon-Rivièri, 1998).

Na realização dos grupos operativos, diversas técnicas podem ser adotadas, indo desde dinâmicas até técnicas teatrais (Martins, 2003). Por se tratar de adolescentes, optou-se pelo uso do lúdico, pois, por meio desse, os jovens conseguem se expressar melhor e há maior possibilidade de transformarem pensamentos e temas em atitudes concretas (Lopes, 2014).

O projeto ocorreu em um município de porte médio, tendo 230 mil habitantes, com caráter urbano e com um Índice de Desenvolvimento Humano Municipal (IDHM) de 0,764. O ensino possui um IDHM de 0,702, com 76,08\% dos adolescentes de 11 a 13 anos de idade com Ensino Fundamental completo.

A escola encontra-se em um bairro periférico da cidade, em que há uma grande gama de alunos de bairros com diferentes padrões sociais. Antes do início dos grupos, foi feita uma reunião com a diretora da escola, para a qual foi apresentada a proposta do projeto. Ao permitir a sua realização, combinaramse as regras, dias e horários em que aconteceriam os encontros, a fim de não se prejudicar a rotina escolar. Os pais autorizaram a participação dos estudantes por meio da assinatura do Termo de Consentimento Livre e Esclarecido (TCLE), 
assim como os alunos assinaram o Termo de Assentimento Livre e Esclarecido (TALE).

Ao todo, foram realizados cinco grupos operativos. Com intervalos quinzenais, todos os encontros ocorreram na própria escola, em sala reservada para tal finalidade. O tempo médio de duração foi de cinquenta minutos. O público alcançado foi de 16 adolescentes, com média de idade de 14 anos. Todos cursavam o $9^{\circ}$ ano do Ensino Fundamental, sendo 7 meninas e 9 meninos.

O projeto foi coordenado por uma docente da Universidade do Estado de Minas Gerais - UEMG, graduada em enfermagem e atuante nas áreas de saúde mental e saúde do adolescente. Dois discentes foram os responsáveis pela coordenação dos grupos, sendo uma aluna do $4^{\circ}$ periodo de psicologia e a outra do $8^{\circ}$ periodo de enfermagem. Pretendeu-se a formação de uma equipe interdisciplinar, pois assim, alcança-se uma percepção mais completa sobre a temática.

Como supramencionado, ocorreram, ao todo, cinco encontros, do mês de outubro a dezembro. Os temas abordados, nessa ordem, foram: "Medo de desafios"; "Colagem com figuras que determinam o papel do homem e da mulher na sociedade"; "Discussão sobre o respeito ao corpo e ao gênero a partir de canções"; "Teatro representativo dos tipos de casais"; e "Jogo: acerte ou erre", sobre infecções sexualmente transmissiveis (IST's) e métodos contraceptivos.

No primeiro encontro, a proposta inicial foi, além de fazer as apresentações, promover uma interação entre os adolescentes e os discentes coordenadores do projeto, bem como a apresentação dos participantes e do tema. Solicitou-se a delimitação de algumas normas internas para o funcionamento grupal, visando a uma melhor dinâmica. As sugestões feitas foram sobre o respeito à opinião do colega: liberdade ao questionar e relatar experiências próprias e garantia de sigilo do grupo, ou seja, os comentários feitos em grupo não seriam divulgados.

Acordadas essas questões entre o grupo, estabeleceu-se o seguinte contrato: esclarecimentos da proposta do trabalho; número de encontros, que seriam cinco, no horário de 10:35 às 11:25, em uma das salas disponibilizadas pela coordenação; o dia da semana como sendo segunda-feira ou quarta-feira, com periodicidade quinzenal. Após o contrato, iniciou-se uma dinâmica de quebra-gelo com o tema "Medo de desafios", no qual foi utilizada uma caixa preta com chocolates. A música tocava e, quando ela parasse, o adolescente deveria escolher abrir ou não a caixa para saber o que tinha. A dinâmica teve como objetivo discutir sobre o medo que se tem do desconhecido. O grupo concluiu que o novo e o diferente podem ser algo positivo. 
Figura 1

\section{Grupo operativo 1, dinâmica "Medo de desafios"}

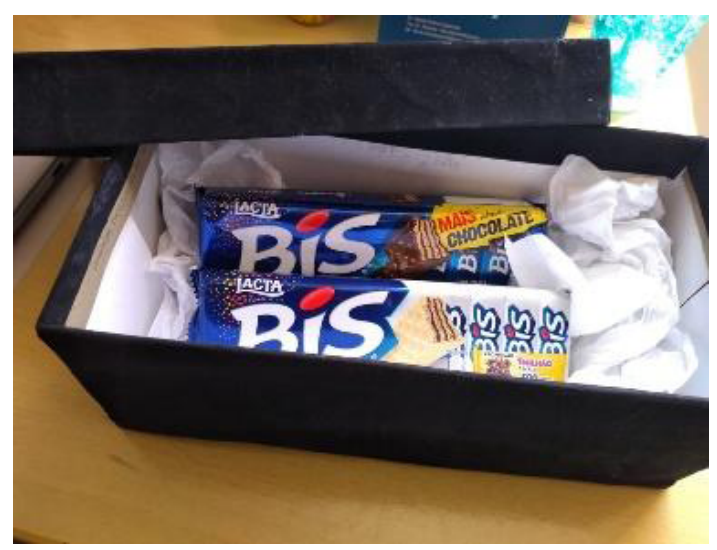

Fonte: acervo pessoal dos pesquisadores.

O tema proposto para o segundo encontro foi discutir o papel do homem e da mulher na sociedade. A sala foi dividida em três grupos. Cada um recebeu duas cartolinas, revistas e material para colagem. Em cada cartolina, os grupos deveriam colocar imagens que remetessem ao universo masculino e ao feminino. Após a realização da colagem, fez-se uma roda e foi proposta uma discussão sobre qual o papel do homem e da mulher na sociedade. Notou-se que, apesar de ainda se ter estereótipos relacionados a objetos, como carros ao universo masculino e utensilios domésticos ao feminino, muitos adolescentes, principalmente as garotas, questionaram os locais sociais, levando a uma discussão que os fez refletir sobre tais espaços e objetos sociais.

Figura 2

Grupo operativo 2, "Papel social do homem e da mulher"

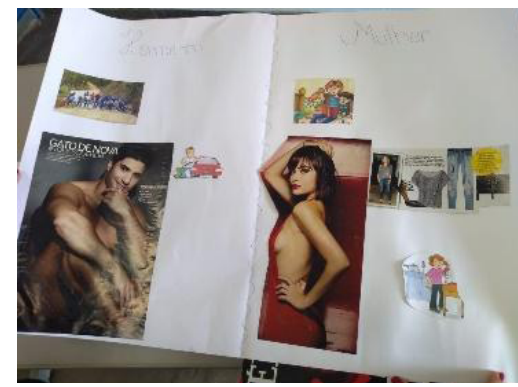


No terceiro encontro, trabalhou-se sobre o "Respeito ao corpo e ao gênero". Para trabalhar o tema utilizou-se da música. Foram escolhidos três musicais com temáticas relativas ao corpo feminino, preconceito de gênero e transexualidade. As músicas escolhidas foram: "Vai, faz a fila" - MC Denny, "A mulher que virou homem" - Jackon do Pandeiro, e poema "Diversidade" - Bráulio Bessa.

Todos receberam a letra impressa e a música foi tocada. Após esse momento, foi aberta a discussão sobre cada letra e seus significados. Os participantes relataram o quanto prestar atenção na letra da música "Vai, faz a fila" era diferente de apenas ouvir a "batida", pois, quando se lê a letra, tem-se a dimensão de como o corpo da mulher é objetificado pelas músicas, principalmente no funk. Na discussão quanto à letra de "A mulher que virou homem", os adolescentes demonstraram curiosidade quanto ao tema da transexualidade e questionaram sobre identidade de gênero e "opção sexual" (expressão utilizada pelos próprios adolescentes, em vez de "orientação", fato que denota certo desconhecimento sobre o assunto), demonstrando confusão com os temas. Durante a discussão houve o relato da experiência de um adolescente que tem um irmão transexual.

As discussões sobre o tema identidade de gênero foram interessantes, pois alguns adolescentes que inicialmente demonstraram certo preconceito foram questionados por outros estudantes e levados a repensar seus posicionamentos. Assim, por meio de relatos e diálogos, evidenciaram que, mesmo não se entendendo o porquê da orientação sexual ou identidade de gênero do individuo, esse deve ser respeitado.

\section{Figura 3}

Grupo operativo 3, "Respeito ao corpo e ao gênero"

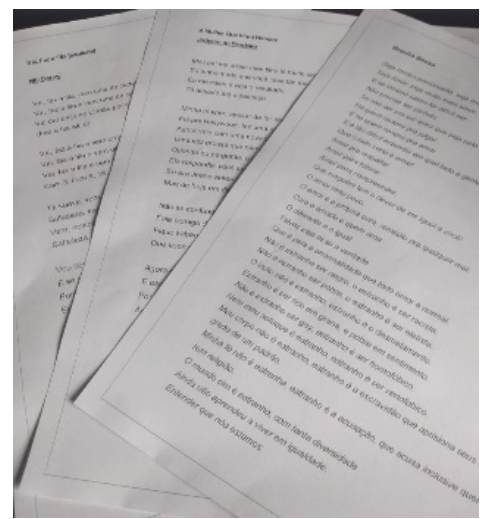

Fonte: acervo pessoal dos pesquisadores 
No quarto encontro, aplicaram-se técnicas teatrais, principalmente a de inversão de papéis (se colocar no lugar do outro). Os integrantes realçaram curiosidade para a realização da proposta. Eles foram organizados em quatro grupos que receberam casos diferentes: o caso de um casal de homens; o caso de um casal de mulheres, outro de um homem transexual e um homem heterossexual, e um casal heterossexual que "descobre" que o filho é homossexual.

Ao ser apresentada tal ideia, percebeu-se uma inquietação por parte dos alunos, já que nunca haviam feito esse tipo de atividade. Além da timidez e do medo do julgamento dos colegas diante da atuação que realizariam. Contudo, à exceção de um, propuseram-se a tentar. O resultado foi surpreende, pois, a técnica foi enriquecedora para eles por estimulá-los a terem empatia com aqueles que fogem do padrão heteronormativo, além de proporcionar uma melhor compreensão sobre os diferentes tipos de gênero, principalmente o transexual, o qual foi teor de dubiedades no encontro anterior.

Ademais, durante a discussão sobre a dinâmica, foi questionado ao aluno que optou por não atuar, o motivo dessa decisão, e se ela seria pelo fato de que ele teria que incorporar um homossexual. Foi nesse espaço de tempo, que muitos se sentiram à vontade para dialogarem sobre suas experiências com casos relacionados ao gênero e à sexualidade, principalmente questões familiares. O rapaz, que ainda não havia interagido com o grupo, então relatou que sua irmã é lésbica, e por tudo que ela passou e representa, ainda era um assunto difícil para ele. O grupo, em geral, concluiu que, além de empatia e respeito, é preciso escutar o outro antes de realizar julgamentos, e é através dessa postura que se tornam possiveis as transformações sociais.

Figura 4

Grupo operativo 4, encenação "Tipos de casais"

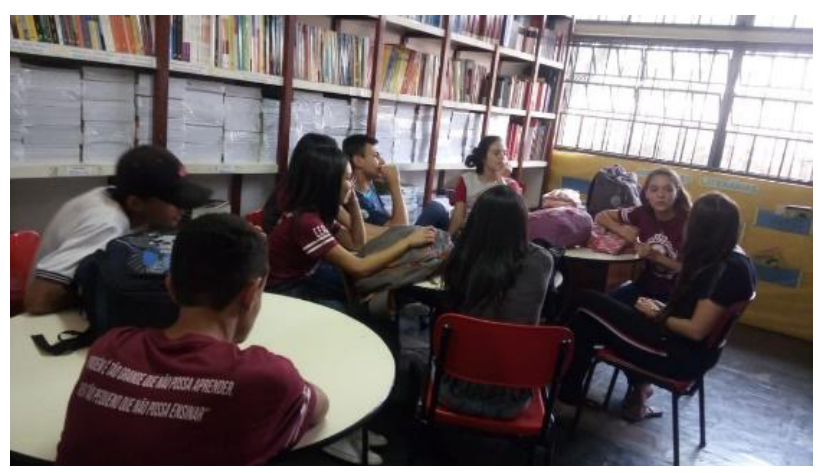

Fonte: acervo pessoal dos pesquisadores.

No encontro final, realizou-se um jogo sobre o conhecimento acerca das IST's e os métodos contraceptivos. Foram formados dois grupos com oito integrantes de ambos os sexos cada. O objetivo era que, quando a coordena- 
dora terminasse de ler cartões com as principais características de IST's e dos métodos contraceptivos, um integrante de cada grupo precisaria correr até o outro lado da sala e tocar o quadro, dando a chance ao seu time de responder corretamente. Caso errassem, a outra equipe podia responder, e se errassem a coordenadora explicava o que era e passava para o próximo cartão, e tudo se repetia.

Foram ao todo 6 cartões - que continham informações sobre o HIV, sífilis, HPV, "camisinha", pílula anticoncepcional e DIU. Caso o grupo que batesse primeiro acertasse, ganhava dois pontos; caso o primeiro errasse e o próximo acertasse, este ganhava 1 ponto; caso os dois errassem, ninguém pontuava.

Os conteúdos eleitos para integrarem o conjunto de informações dos cartões sobre as IST's foram as formas de transmissões, sintomas, formas de prevenção, dados estatísticos de indivíduos portadores dessas infecções e o ciclo do patógeno. Já no dos métodos, abordou-se a forma como agem, como se proteger de infecções e/ou gravidez, forma de utilização de cada um deles (destacando-se a necessidade de acompanhamento ginecológico para as meninas), e os diversos tipos de infecção.

Entre todos os encontros, percebeu-se que esse foi o que trouxe maior dificuldade aos adolescentes, e que muitos desconheciam sobre a importância dos métodos contraceptivos, especialmente da camisinha - a única que previne infecções e gravidez não planejada. Para o encerramento, foi entregue uma mensagem com uma bala de agradecimento. Foi aberto o espaço na roda de conversa para sanar dúvidas sobre o assunto discutido, e logo ocorreu a despedida.

Figura 5

Grupo operativo 5, "Jogo de IST's e contraceptivos"

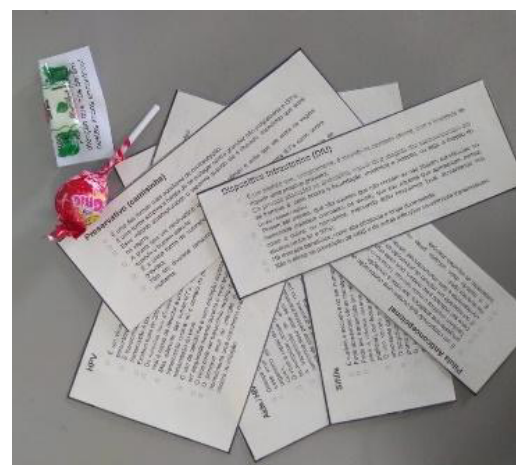

Fonte: acervo pessoal dos pesquisadores. 
Os alunos relataram que a experiência de aprendizado em forma de grupo operativo com atividades lúdicas foi efetiva, pois estariam "cansados" de aulas formais e palestras em que apenas ouviam e pouco eram escutados.

Um dos limitadores do projeto foi que, por serem os encontros da quarta-feira no dia da aula de educação física, alguns participantes acabavam não comparecendo. O tempo também foi um dos limitadores, visto que em muitas ocasiões os encontros atrasaram devido a outras atividades.

\section{DISCUSSÃO}

Ao discutir gênero e sexualidade com os adolescentes que participaram do grupo operativo, ficou evidente, por meio das ações desenvolvidas na escola em relação à temática, que para alguns a compreensão do conceito, a prevenção das IST's, contraceptivos, gravidez precoce e outros assuntos abordados ainda é limitada. Compreendeu-se que o conhecimento dos adolescentes sobre as temáticas abordadas é incipiente e há resistência por parte de alguns em discutir ou contracenar, fato esse que dificulta a superação das concepções fragmentadas pautadas nos valores e princípios conservadores da moralidade e da religiosidade.

A escola é um espaço onde a diversidade de culturas, religiões, crenças, estilos de vida, pensamentos, etnias, sexo, identidades está presente e ela representa um lugar importante para se trabalhar conhecimentos, habilidades e mudanças de comportamento, pois é local em que o adolescente permanece o maior tempo do seu dia (Gomes, 2013). Portanto, torna-se um ambiente ideal e adequado para o desenvolvimento de ações educativas, possivel de atuação nas diferentes áreas dos saberes humanos. No contexto atual, há um embate sobre a discussão da temática no espaço escolar; tais resistências evidenciam um modelo de sociedade patriarcal, machista, heteronormativo e preconceituoso (Mantovani et al., 2016).

O Ministério da Educação (MEC) considera a escola como parceira da família e da sociedade na promoção da saúde das crianças e dos adolescentes, e atribui, às escolas, a corresponsabilidade na orientação da criança desde o pré-escolar ao Ensino Fundamental. "No diálogo entre a escola e as familias, pretende-se que a sexualidade deixe de ser tabu e, ao ser objeto de discussão na escola, possibilite a troca de ideias entre esta e as familias" (Brasil, 1998, p. 304). Por outro lado, a literatura também aponta a dificuldade que escolas e familias ainda apresentam para abordar, com crianças e jovens, o tema da sexualidade (Nogueira et al., 2011).

Segundo Nogueira et al. (2011), o assunto é polêmico na esfera pública e na esfera privada. A sexualidade, tratada sem o descobrir do próprio "eu" e do reconhecimento do outro, torna-se pouco significativa, não alcançando discussões mais profundas sobre valores individuais e sociais, o que de fato importa no processo educativo. Desse modo, reconhece-se que uma abordagem trans- 
disciplinar da sexualidade requer boa formação dos professores e profissionais de saúde e materiais educativos adequados.

Em um estudo realizado em uma escola do Paraná, os próprios professores afirmam estarem despreparados para trabalharem com as questões da diversidade na escola, especialmente sobre gênero e sexualidade (Mantovani et al., 2016). Para tanto, informações e orientações a respeito da anatomia e fisiologia do aparelho reprodutor, muito embora sejam necessárias, não são suficientes. Falar sobre sexualidade é referir-se também a sentimentos, emoções e afetos fundamentais no desenvolvimento e na vida psíquica do ser humano (Brêtas et al., 2015).

Nessa perspectiva, o cenário nas escolas é preocupante, pois não se percebe a vinculação dos conteúdos ao contexto dos alunos, principalmente daqueles que tratam de temas que se destinam a auxiliar o jovem na compreensão do próprio corpo e de suas relações amorosas, bem como do desenvolvimento da responsabilidade pela sua saúde e do outro com quem se relaciona. Para temas como a sexualidade, que requerem não só domínio do conhecimento biológico, mas também reflexão sobre a vida e o ambiente em que se vive, construir novos conhecimentos demanda processos singulares e criativos que preparem o cidadão para o seu viver cotidiano (Nogueira et al., 2011).

\section{CONCLUSÃO}

O projeto revelou-se de grande importância, tendo-se em vista os resultados alcançados pelos relatos dos adolescentes. Por meio dos dados supramencionados, percebe-se que há falhas de comunicação sobre gênero e sexualidade nas escolas, conteúdo vital para a formação biopsicossocial dos adolescentes. Diante disso, verifica-se que é urgente a abordagem do assunto em sala de aula.

Por entender que se trata de temática sensivel e envolta por tabus, acredita-se que as parcerias entre escolas e universidades sejam uma estratégia interessante por se tratar de um novo olhar sobre a temática, não ficando essa restrita a disciplinas e palestras. Esse trabalho conjunto, realizado em forma de diálogo, acaba por criar um vínculo grupal e o respeito pelo outro, como foi notado pelo presente trabalho.

Ademais, sugere-se a realização de educação permanente dos professores das diversas disciplinas, pois, como educadores, os professores influenciam, pelo que falam e representam, a formação dos jovens. Além disso, os conteúdos diversos comunicam-se com os assuntos de gênero e sexualidade, e devem ser pensados de diferentes ângulos.

Assim, acredita-se que essas considerações contribuam para a mudança desse cenário e que um diálogo eficiente será alcançado. Por fim, através do percurso realizado e de tudo posto, há a expectativa de que o projeto seja 
aplicado novamente em novas escolas e que o relato de experiência sirva de farol para outros pesquisadores e educadores da área.

\section{Financiamento:}

Bolsa de iniciação científica pelo Programa de Apoio a Projetos de Extensão da UEMG - PAEx /UEMG.

\section{Agradecimentos:}

Agradecemos o apoio da Liga Acadêmica de Saúde Mental: Insanos da UEMG. 


\section{REFERÊNCIAS}

Brasil. Ministério da Educação e Cultura. (1998). Parâmetros curriculares nacionais: temas transversais. Brasilia: MEC/SEF.

Brêtas, J. R. S., et al. (2015). Corpo, gênero e sexualidade: práticas de extensão universitária. Revista Ciência em Extensão, 11(1), 100-115.

Butler, J. (2018). Problemas de gênero, feminismo e subversão da identidade. 16 ed. Rio de Janeiro: Civilização Brasileira.

Campos, H. M., et al. (2018, jul./set.). Diálogos com adolescentes sobre direitos sexuais na escola pública: intervenções educativas emancipatórias! Revista Pesquisas e Práticas Psicossociais, São João del-Rei, 13(3), 1-16.

Cerqueira, D. C., et al. (2018). Atlas da Violência, 2018.

Domingues, E., et al. (2018, jul./set). Oficinas com adolescentes do MST: sexualidade, diversidade sexual e gênero. Revista Pesquisas e Práticas Psicossociais, São João del-Rei, 13(3), 1-15.

Gomes, C. de M. (2013, jan./mar.). Vivência em grupo: sexualidade, gênero, adolescência e espaço escolar. Revista de APS, 16(1), 103-111.

Lopes, G. T. (2014). Percepções de adolescentes sobre uso/dependência de drogas: o teatro como estratégia pedagógica. Escola Anna Nery - Revista de Enfermagem, 18(2), 202-208. http://dx.doi.org/10.5935/1414-8145.20140029.

Mantovani, T. M., \& Martelli, A. C. (2016). Sexualidade e adolescência: conversas sobre diversidade sexual e de gênero na escola. Cadernos PDE, 2, 1-64.

Marcon, A. N., Prudêncio, L. E. V., \& Gesser, M. (2016, mai./ago.). Políticas públicas relacionadas à diversidade sexual na escola. Psicologia Escolar e Educacional, São Paulo, 20(2), 291-302. http://dx.10.1590/2175-3539/2015/0202968.

Martins, S. T. F. (2003, jan./jun.). Processo grupal e a questão do poder em Martín-Baró. Psicologia \& Sociedade, Porto Alegre, 15(1), 201-217. http://dx.doi. org/10.1590/S0102-71822003000100011.

Morais, S. P., Da Silva Brêtas, J. R., \& DeSouza Vitalle, M. S. (2020). Educação escolar, sexualidade e adolescência: uma revisão sistemática. Journal of Health Sciences, 20(3), 221-230. http://dx.doi.org/10.17921/2447-8938.2018v20n3p221-230.

Nogueira, M. J., et al. (2011). Criação compartilhada de um jogo: um instrumento para o diálogo sobre sexualidade desenvolvido com adolescentes. Ciência \& Educação (Bauru), 17(4), 941-956. http://dx.doi.org/10.1590/ S1516-73132011000400011. 
Pichon-Rivièri, E. (1998). Teoria do Vínculo. São Paulo: Martins Fontes.

Trifoni, D. N. (2013). Análise da Determinação Social da Saúde: olhares e vozes de adolescentes do Itapoã - DF, 147f. [Dissertação, Mestrado em Ciências da Saúde, Faculdade de Ciências da Saúde, Universidade de Brasilia, Brasilia]. http:// ecos.unb.br/wp-content/uploads/2015/11/2013_DayanaNataliaTrifoni.pdf.

Data de submissão: 14/04/2020

Data de aceite: 20/11/2020 